\title{
Study on prevalence of hypothyroidism in pregnancy in rural population of Pilkhuwa, Hapur, U.P.
}

\author{
Alpana Bansal ${ }^{1}$, Meena Saxena ${ }^{2, *}$, Mukesh Bansal $^{3}$ \\ ${ }^{1}$ Associate Professor, ${ }^{2,3}$ Assistant Professor, ${ }^{1,2}$ Dept. of Obstetrics and Gynecology, ${ }^{3}$ Dept. of Anatomy, ${ }^{1}$ Saraswati Institute of \\ Medical Science, Anwarpur, Hapur, ${ }^{2}$ Governement Medical College, Banda, Uttar Pradesh, ${ }^{3}$ Govt. Medical college, Badaun, \\ Uttar Pradesh, India
}

*Corresponding Author:

Email: bansalmukesh4@gmail.com

\begin{abstract}
Introduction: Thyroid dysfunction is a common endocrine disorder in pregnancy. Thyroid hormones are necessary for development of fetal brain during pregnancy. Thyroid dysfunction during pregnancy has significant adverse effects such as preterm delivery, preeclampsia, miscarriage and low birth weight. In India one of the common health issues is hypothyroidism in pregnant patient. There is lack of data regarding prevalence of hypothyroidism in pregnancy while the problem is increasing day by day.

Aim \& Objective: 1. To study the prevalence of Hypothyroidism in rural population of Pilkhuwa, Hapur; 2. To study the age and trimester of pregnancy in relation to Hypothyroidism; 3 . To Early diagnosis of disease so as to reduce morbidity \& mortality; 4 . To suggest corrective measures based upon the information gathered in the study.

Materials and Methods: A study was conducted at Yashoda clinic Pilkhuwa Hapur. Patients attending antenatal clinic and checkup were included and TSH reports were collected.

Observation: A total of 101cases were included in the study that came for antenatal check-up. Out of 101 cases, 59 are euthyroid. 16 cases had TSH between 2.5 -3.0. 26 cases had TSH from 3.0 -7.5. None of the patient had TSH equal to or above 10 units.

Result: In first trimester 7 cases out of 81 which required treatment with eltroxin and needed follow up. 32 out of 81 cases required only follow up.

In second trimester 3 cases out of 15 which required treatment with eltroxin and follow up. 7 cases out of 15 required follow up. In third trimester none of the cases in third trimester required treatment or follow up.

Conclusion: Hypothyroidism is an important health issue among pregnant women which can cause several complications in ongoing and future pregnancies like recurrent abortions, infertility, PIH, preterm labour APH, PPH. All pregnant women and ladies who are planning pregnancies should be screened for thyroid disease.
\end{abstract}

Keywords: Hypothyroidism, India, Prevalence, subclinical hypothyroidism, Undetected hypothyroidism.

\section{Introduction}

Thyroid gland is an important gland, secretes thyroxin hormone. Thyroxin is needed for cellular oxidation and neurological development. ${ }^{1}$ It regulates metabolism and hormone production in our body. In early pregnancy demand of thyroid hormones increases, because thyroid hormones are essential for fetal brain development, at this phase of time fetus depends on maternal thyroid hormones. The fetal thyroid gland starts producing hormone from 10 weeks of gestation, ${ }^{2}$ but it is not in sufficient amount so fetus depend up to 20 weeks of gestation on the maternal thyroxin. ${ }^{3} \mathrm{~T} 4$ concentrations reach adult levels at 36 weeks of gestation, while T3 always remains below adult concentrations. ${ }^{4}$ During pregnancy as demand of thyroid hormone increases, serum TSH level also increases, and it is called primary maternal hypothyroidism. Secondary maternal Hypothyroidism is- increased Serum TSH level due to TSH Secreting pituitary tumour, thyroid hormone resistance etc.

Primary maternal hypothyroidism is of two types-

1. Overt Hypothyroidism

2. Sub clinical Hypothyroidism
Overt hypothyroidism is characterised by increase serum TSH level with low serum T4 level. But if serum TSH level is equal or more than $10 \mathrm{~m} \mathrm{IU/L}$ than it is overt hypothyroidism irrespective of serum $\mathrm{T} 4$ level. Sub clinical Hypothyroidism is characterised by increase serum TSH level (below $10 \mathrm{~m}$ IU/L) with normal serum T4 level.

Hypothyroidism is $2^{\text {nd }}$ commonest endocrine disorder during pregnancy ${ }^{5}$. Iodine is an important part of thyroid hormone, so its requirement also increases during pregnancy. Deficiency of Iodine increases chances of Hypothyroidism. ${ }^{6}$ In iodine deficient areas prevalence of hypothyroidism is $1-2 \%$.

Hypothyroidism in pregnancy leads to impaired fetal development, and can lead to-Miscarriage, pregnancy induced hypertension, pre-eclampsia, placental abruption, anaemia, postpartum haemorrhage and stillbirth during pregnancy, ${ }^{7,8}$ increase neonatal mortality; and impaired neurological development, faltering growth and cretinism in child hood. ${ }^{9}$

Thyroid autoimmunity is common in young women. Studies have shown a $3-20 \%$ prevalence of circulating thyroid antibodies in women during or 
shortly after pregnancy. These women are at risk of becoming hypothyroid during pregnancy. ${ }^{10-11}$

Impaired intelligence and psychomotor development has led to the suggestion that women should be screened for hypothyroidism, either by serum TSH or free $\mathrm{T}_{4}$. Mild TSH elevation did not put the fetus at risk. An increased risk of fetal deaths in women with TSH equal to or greater than $10 \mathrm{~m}$ IU/L has been reported. ${ }^{9,12}$

\section{Aims and Objectives}

Aim of this study is:

1. To study the prevalence of Hypothyroidism in rural population of Pilkhuwa, Hapur.

2. To study the age and trimester of pregnancy in relation to Hypothyroidism.

3. To Early diagnosis of disease so as to reduce morbidity \& mortality.

4. To suggest corrective measures based upon the information gathered in the study.

\section{Materials and Methods}

Pregnant women those attended OPD for antenatal check-up were taken. A detailed history and clinical examination was done than venous samples were collected.

Samples were collected either empty stomach or after light meals avoiding fatty meals.

Inclusion criteria: Normal pregnant women those attended OPD for antenatal check-up were included in the study.

Exclusion criteria: All others with diabetes, collagen disease, and heart disease in pregnancy were excluded.

One hundred one pregnant women in the age group of 18 to 40 years, who attended the antenatal clinic, were personally followed and, TSH screening was done using fasting serum sample at first check up and as early as the pregnancy was confirmed.

In selected patients whose TSH was increase, FT4 was done to confirm diagnosis and treatment was started. TSH was repeated at 8 weeks interval and post natally.
If there was an excess weight gain, preterm pains and pregnancy-induced hypertension, TSH was repeated. High risk women were given special attention.

Diagnostic criteria in pregnancy: Pregnancy-specific and trimester specific reference levels for $\mathrm{TSH}$ are as follows:

Ist trimester - 0.1-2.5mIU/1;

IInd trimester - 0.2-3mIU/1;

IIIrd trimester $-0.3-3 \mathrm{mIU} / 1$.

\section{Observation}

A total of 101 cases were included in the study that came for antenatal check-up.

Table 1: Age wise distribution of patients

\begin{tabular}{|l|c|}
\hline Age [years] & No. of cases \\
\hline $18-25$ & 77 \\
\hline $26-30$ & 20 \\
\hline $31-35$ & 3 \\
\hline $36-40$ & 1 \\
\hline
\end{tabular}

Out of 101patients enrolled in the study

$76.23 \%$ of patients were between $18-25 \mathrm{yrs}$,

$19.80 \%$ were between $26-30 \mathrm{yrs}$,

$2.97 \%$ were between $31-35$ yrs,

$0.99 \%$ were between $36-40$ yrs.

It shows maximum number of cases are young between $18-30$ yrs.

Table 2: Distribution of patients according to TSH reports

\begin{tabular}{|l|c|}
\hline \multicolumn{1}{|c|}{ TSH report } & No. of cases \\
\hline $0.02-2.5$ & 59 \\
\hline $2.5-3.0$ & 16 \\
\hline $3.0-7.5$ & 26 \\
\hline $10.0->$ & 0 \\
\hline
\end{tabular}

Out of 101 cases

59 are euthyroid.

16 cases had TSH between $2.5-3.0$.

26 cases had TSH from $3.0-7.5$.

None of the patient had TSH equal to or above 10 units.

Table 3: Trimister wise study of prevelence of hypothyroidism

\begin{tabular}{|l|l|l|l|l|}
\hline $\begin{array}{l}\text { S.No } \\
.\end{array}$ & Trimister & Cases & $\begin{array}{l}\text { Subclinical } \\
\text { Hypothyroidism }\end{array}$ & $\begin{array}{l}\text { Overt } \\
\text { Hypothyroidism }\end{array}$ \\
\hline 1 & First Trimister & 81 & 32 & 7 \\
\hline 2 & Second Trimister & 15 & 7 & 3 \\
\hline 3 & Third Trimister & 5 & 0 & 0 \\
\hline
\end{tabular}

In first trimester out of 81 cases

32 had subclinical hypothyroidism and i.e. $39.50 \%$,

7 had overt hypothyroidism, i.e. $8.75 \%$.

In second trimester out of 15 cases

7 had subclinical hypothyroidism i.e. $46.66 \%$,

3 had overt hypothyroidism i.e. $20 \%$. 


\section{Results}

Among the 101 pregnancies studied, maximum numbers of patients were in age group of 18 -30 years.

We arranged the women according to TSH values into three groups.

Group 1 first trimester - had

7 cases out of 81 which required treatment with eltroxin and needed follow up.

32 out of 81 cases required only follow up.

Group 2 - second trimester had

3 cases out of 15 which required treatment with eltroxin and follow up.

7 cases out of 15 required follow up.

Group 3 - third trimester

None of the cases in third trimester required treatment or follow up.

\section{Discussion}

In Pregnancy there is extra load on thyroid gland due to increase thyroxin binding globulin, increased demand for iodine, and thyroid stimulation by HCG. ${ }^{13}$ These are some factors due to which borderline hypothyroid women after conception, can develop sub clinical or overt hypothyroidism.

Fetus depends in the first 12 weeks on the mother for thyroxine. ${ }^{14} \mathrm{~A}$ substantial amount of thyroxin is transferred across the placenta. Placental de-iodinases can convert T4 to T3. Fetus needs thyroxin for brain development, growth, and lung maturation. ${ }^{14}$

Untreated hypothyroidism in pregnancy is associated with adverse maternal effects. During pregnancy, it is known to result in miscarriages (in early pregnancy), recurrent pregnancy losses, anaemia, pre-eclampsia, gestational diabetes, abruption placentae, postpartum haemorrhage, increased caesarean sections due to fetal distress, and rarely myopathy and even congestive heart failure (CHF) in severe cases ${ }^{7}$. Hypothyroidism results in preterm births, intrauterine growth restriction, intrauterine fetal demise, respiratory distress and increased perinatal mortality (PNM). In newborns, it leads to cognitive, neurological and developmental impairment ${ }^{1}$. Thyroid hormone is critical for fetal brain development.

Hypothyroidism has also been associated with adverse effects on intelligence quotient (IQ) and neuropsychological development. ${ }^{15}$ Following the diagnosis of overt hypothyroidism, levo thyroxin replacement should be commenced, aiming to achieve a TSH level within the trimester-specific pregnancy reference range. ${ }^{16}$ The majority of pregnant women with pre-existing hypothyroidism will need increments of their levothyroxine dose by $25-50 \%$, often within four to eight weeks of gestation and the dose increment tends to plateau by 16 weeks of gestation ${ }^{17}$. Such a dose increment should take place immediately on confirmation of a missed cycle or a positive pregnancy test.
Internationally the prevalence of hypothyroidism in pregnancy is $2-3 \%$. Of these, $0.3-0.5 \%$ is $\mathrm{OH}$ and 2$2.5 \%$ is SCH. ${ }^{18}$ Studies have demonstrated $60 \%$ risk of fetal loss and $22 \%$ risk of gestational hypertension with untreated $\mathrm{OH}$. A firm association between $\mathrm{OH}$ and adverse risk to the maternal-fetal unit has been demonstrated. The miscarriage rate in $\mathrm{SCH}$ is $6 \%$ vs $3.6 \%$ in euthyroid women. ${ }^{16}$ A two-to three fold increased risk of pregnancy related complications was demonstrated in untreated women with $\mathrm{SCH}$.

Nationally prevalence of hypothyroidism in pregnancy in the Indian population is $4.8-12 \%$. Reported prevalence by Sahu et al 2010 was $6.47 \%$ with $4.58 \%$ as $\mathrm{OH}$. Another Indian study has reported the prevalence of hypothyroidism to be $12 \%$, of which $3 \%$ was $\mathrm{OH}$ and $9 \%$ was $\mathrm{SCH}$. TPO antibodies are positive in around $50 \%$ pregnant women in $\mathrm{SCH}$, as compared to $7 \%$ in euthyroid pregnant women.

Incidence of hypothyroidism in women with recurrent pregnancy loss up to 12 weeks is $4.1-16.6 \%$. The miscarriage rate in $\mathrm{SCH}$ is $12-21 \%$, while in $\mathrm{OH}$, it is $21 \%$. The rate of stillbirth is $0-16.6 \%$ for $\mathrm{SCH}$ and $4.2 \%$ for $\mathrm{OH}$. The incidence of pre-eclampsia has been reported as $16 \%$ for $\mathrm{OH}$ and $22 \%$ for $\mathrm{SCH}$. The incidence of abruptio placentae is $16 \%$ for $\mathrm{OH}$ and $5 \%$ for SCH. Intrauterine Growth Restriction (IUGR) prevalence is $25 \%$ in $\mathrm{OH}$ and $8 \%$ in $\mathrm{SCH}$, while the incidence of pre-term delivery is $33 \%$ with $\mathrm{OH}$ and $11 \%$ with $\mathrm{SCH}$.

Our study also shows that prevalence of overt hypothyroidism is $8.75 \%$, and $20 \%$ in first and second trimester respectively. We found that prevalence of subclinical hypothyroidism in our study group as $39.50 \%, 46.66 \%$ in first and second trimester respectively. This study shows that this may be the tip of iceberg, there may be larger section of pregnant women who do not has asses to the facility of TSH screening.

Even government Hospitals in U.P. do not include TSH levels in antenatal check-up despite large section of poor and rural patients go to government hospitals for registration of delivery.

Thus if maternal levels of thyroxin are not well maintained in pregnancy, fetus is at risk. This demands an early or even prenatal FT4, TSH screening and more frequent fetal monitoring of thyroxin levels in pregnancy.

\section{Conclusion}

According to our study hypothyroidism is increasing day by day .It is an important health issue among pregnant women which can cause several complication in ongoing and future pregnancies like recurrent abortions, infertility, PIH, preterm labour $\mathrm{APH}, \mathrm{PPH}$.

All pregnant women and ladies who are planning pregnancies should be screened for thyroid disease. 
Thyroid Screening is a must at first booking, ideally prenatally to prevent miscarriages. T3, T4, FT4, TSH screening is able to pick up even borderline cases $0.25-2 \mathrm{mIU} / \mathrm{ml}$ recognized as normal ref. range for TSH.

Repeat TSH screening to be done at 8 weeks interval or each trimester, as and when the situation dictates. Adequate replacement therapy should be given when TSH is high

Conflict of interest: The authors declare that they have no conflict of interest.

Funding: This work did not receive funding for any aspect of compilation or publication.

\section{References}

1. Haddow JE, Palomaki GE, Allan WC et al. Maternal thyroid deficiency during pregnancy and subsequent neuropsychological development of the child. N Engl J. Med 1999;341:549-55.

2. D.A. Fisher Fetal thyroid function: diagnosis and management of fetal thyroid disorders Clin Obstet Gynecol, 40 (1997), pp.16-31.

3. M. Puig-Domingo, L. Vila the implications of iodine and its supplementation during pregnancy in fetal brain development Curr Clin Pharmacol, 8 (2013), pp.97-109.

4. J.G. Thorpe-Beeston, K.H. Nicolaides, A.M. McGregor Fetal thyroid function Thyroid, 2 (1992), pp. 207-217

5. M.P.J. Vanderpump the epidemiology of thyroid disease Br Med Bull, 99 (2011), pp. 39-51

6. M.B. ZimmermannThe adverse effects of mild-tomoderate iodine deficiency during pregnancy and childhood: a review Thyroid, 17 (2007), pp.829-35.

7. S.N. Ajmani, D. Aggarwal, P. Bhatia, M. Sharma, V. Sar abhai, M. Pau 1 Prevalence of overt and subclinical thyroid dysfunction among pregnant women and its effect on maternal and fetal outcome J Obstet Gynaecol India, 64 (2014), pp.105-10.

8. S. Maraka, N.M. SinghOspina, D.T. O'Keeffe, A.E. Espi nosaDeYcaza, M.R. Gionfriddo, P.J.Erwin, et al. Subclinical hypothyroidism in pregnancy: a systematic review and meta-analysis Thyroid, 26 (2016),pp. 580-90.

9. Thompson CC, Potter GB. Thyroid hormone action in neural development. Cereb Cortex 2000;10:939-45.

10. Liu H., Shan Z., Li C., Mao J., Xie X., Wang W., et al. Maternal subclinical hypothyroidism, thyroid autoimmunity, and the risk of miscarriage: a prospective cohort study Thyroid, 24 (2014), pp.1642-9.

11. Gayathri R, Lavanya S, Raghavan K. Subclinical hypothyroidism and autoimmune thyroiditis in pregnancy study in South Indian subjects. J Assoc Physicians India. 2009;57:691-3. [PubMed]

12. Spong CY. Subclinical hypothyroidism: should all pregnant women be screened? Obstet Gynecol 2005;105:235-6.

13. Stirrat GM. Aids to Obstetrics and Gynecology for MRCOG. London: Churchill Livingstone, 1983:p87.

14. Lazarous JH. Thyroid function between 11-16 weeks of gestation - A critical time for fetal development. 13th International Thyroid Congress Commercial Exhibition 2005. Poster Abstract No.219.

15. Shane O. Le Beau, Susan J. Mandel. Thyroid Disorders During Pregnancy Endocrinology and Metabolism Clinics of North America, Volume 35, Issue 1, Pages 11736.
16. Abalovich M, Gutierrez S, Alcaraz G et al. Overt and subclinical hypothyroidism complicating pregnancy. Thyroid 2002;12:63-8.

17. Negro R, Schwartz A, Gismondi R, Tinelli A, Mangieri $\mathrm{T}$, Stagnaro- Green A. Universal screening vs. casefinding for detection and treatment of thyroid hormonal dysfunction during pregnancy. J Clin Endocrinol Metab.2010;95:1699-707. [PubMed]

18. Ajmani Sangita Nangia, Aggarwal Deepa, Bhatia Pushpa, Sharma Manisha, Sarabhai Vinita, Paul Mohini. Prevalence of Overt and Subclinical Thyroid Dysfunction among Pregnant Women and Its Effect on Maternal and Fetal Outcome. JOGI, March- April 2014;64(2). 